\title{
A meshfree model for plant tissue deformations during drying
}

\author{
H. C. P. Karunasena ${ }^{1} \quad$ W. Senadeera ${ }^{2} \quad$ R. J. Brown ${ }^{3}$ \\ Y. T. $\mathrm{Gu}^{4}$
}

(Received 20 December 2013; revised 1 May 2014)

\begin{abstract}
Plant tissue has a complex cellular structure which is an aggregate of individual cells bonded by middle lamella. During drying processes, plant tissue undergoes extreme deformations which are mainly driven by moisture removal and turgor loss. Numerical modelling of this problem becomes challenging when conventional grid-based modelling techniques such as finite element and finite difference methods are considered due to grid-based limitations. This work presents a meshfree approach to model and simulate the deformations of plant tissue during drying. This method demonstrates the fundamental capabilities of meshfree methods in handling extreme deformations of multiphase systems. A simplified two-dimensional tissue model is developed by aggregating individual
\end{abstract}

http://journal.austms.org.au/ojs/index.php/ANZIAMJ/article/view/7857 gives this article, (C) Austral. Mathematical Soc. 2014. Published May 8, 2014, as part of the Proceedings of the 11th Biennial Engineering Mathematics and Applications Conference. ISSN 1446-8735. (Print two pages per sheet of paper.) Copies of this article must not be made otherwise available on the internet; instead link directly to this URL for this article. 
cells while accounting for the stiffness of the middle lamella. Each individual cell is simply treated as consisting of two main components: cell fluid and cell wall. The cell fluid is modelled using smoothed particle hydrodynamics and the cell wall is modelled using a discrete element method. Drying is accounted for by the reduction of cell fluid and wall mass, and turgor pressure, which causes local deformations of cells, eventually leading to tissue scale shrinkage. The cellular deformations are quantified using several cellular geometrical parameters and a good agreement is observed when compared to experiments on apple tissue. The model is also capable of visually replicating dried tissue structures. The proposed model can be used as a step in developing complex tissue models to simulate extreme deformations during drying.

\section{Contents}

1 Introduction

C112

2 Modelling of individual cells and tissue

C113

2.12 D representation of plant cells in tissue . . . . . . . .

C113

2.2 Cell wall model . . . . . . . . . . . . . . . . . C C114

2.3 Cell fluid model . . . . . . . . . . . . . . . . . . C116

2.4 Tissue generation . . . . . . . . . . . . . . C117

2.5 Computational setup and validation . . . . . . . . . C117

2.6 Computer implementation and visualization . . . . . . C C119

3 Results and discussion

C120

3.1 Selection of an optimal particle scheme . . . . . . . . C120

3.2 SEM image analysis of dried tissue samples . . . . . . . . . C C121

3.3 Simulation of cellular deformations . . . . . . . . . C C122

3.4 Model sensitivity to the force coefficient of cell wall contractions C124

3.5 Model sensitivity to the cell wall bending stiffness . . . . . C C128

3.6 Model sensitivity to the cell wall Young's modulus . . . . . C C132 


\section{Introduction}

Plant food materials contain up to $90 \%$ water [1] and as a result are highly susceptible to biological spoilage. Drying is a technique used to remove excess water from food materials, which helps to significantly reduce biological reactions and related spoilage. During drying, significant microstructural deformations occur that eventually influence bulk level deformations and physical property changes of the food material. These cellular and bulk level deformations are mainly driven by the moisture content of the plant tissue [2], drying temperature [3] and cell turgor pressure [4]. Such structural deformations need to be analysed and carefully controlled in the quality control and process optimization of food engineering. To assist such industrial applications, microscale empirical [5] and theoretical models [6] are frequently developed on plant-based food materials. However, not much research has been conducted on numerical models for microscale deformations of food materials during drying. Several plant cell numerical models are based on finite element methods (FEM) and finite difference methods (FDM) [7, 8, 9]. These models were primarily developed for basic cell mechanical behaviour studies rather than drying. Extending these models to cellular drying mechanisms is highly challenging due to the fundamental limitations of such methods in treating the complex physics of dried cells and tissue. These limitations include: multiphase phenomena due to the presence of liquid, solid and gas phases; excessive boundary deformations; discrete characteristics of the tissue materials due to the aggregated cellular structure; and multiscale relationship between sub-cellular scale and bulk scale deformations. Recently developed meshfree methods $[10,11]$ and variations $[12,13]$ are proving more suitable since they do not use any interconnected grids, unlike grid-based techniques 
such as FEM and FDM [10].

Smoothed particle hydrodynamics ( $\mathrm{SPH}$ ) is a well researched particle-based meshfree technique, initially developed for astrophysical applications [14]. SPH defines a given problem domain as a set of non-interconnected particles that carry physical properties and evolve with time. SPH is quite adaptive and new physics is easily incorporated [10]. With the use of SPH and a discrete element method (DEM), Van Liedekerke et al. $[15,16]$ recently developed a comprehensive numerical model to study the basic mechanical responses of plant cells. However, there is a clear research gap for a numerical model based on meshfree methods, specifically for deformations of plant cells during drying. To fulfil this gap, Karunasena et al. [17, 18, 19, 20] developed a SPH-DEM based single cell model to study drying related cellular deformation. This is a continuation of that work and our main focus here is to introduce a basic tissue model based on the previous single cell model with several improvements.

\section{Modelling of individual cells and tissue}

\section{$2.12 \mathrm{D}$ representation of plant cells in tissue}

Figure 1(a) shows a simplified cell arrangement of tissue where the basic shape of any plant cell is approximated by a cylinder with a uniform longitudinal cross section (Figure 1(b)). Here, the top circular surface of any such cell is used as a 2D model of the whole cell [19, 20]. The model incorporates two main components: cell fluid and cell wall. SPH is used to model the cell fluid by approximating it to an incompressible viscous fluid. The cell wall is approximated by a solid boundary and modelled with DEM. Then, in order to satisfy the general modelling requirements of both SPH and DEM, the problem domain is described by two sets of particles: cell fluid particles and cell wall particles, as shown in Figure 1(c). 


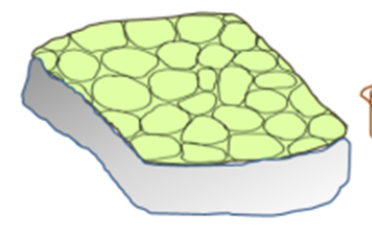

(a)

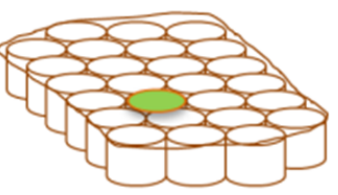

\section{Fluid particles}
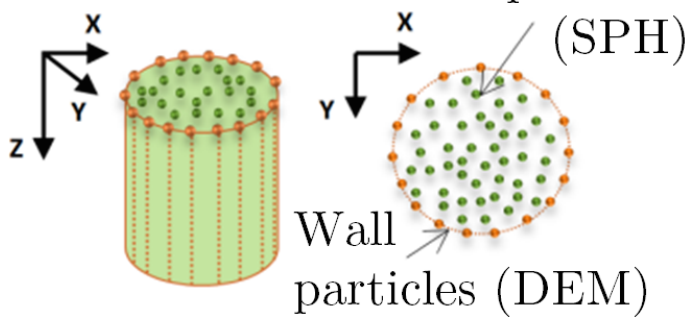

(c)
Cell wall

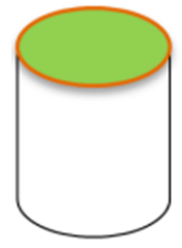

Cell fluid

(b)
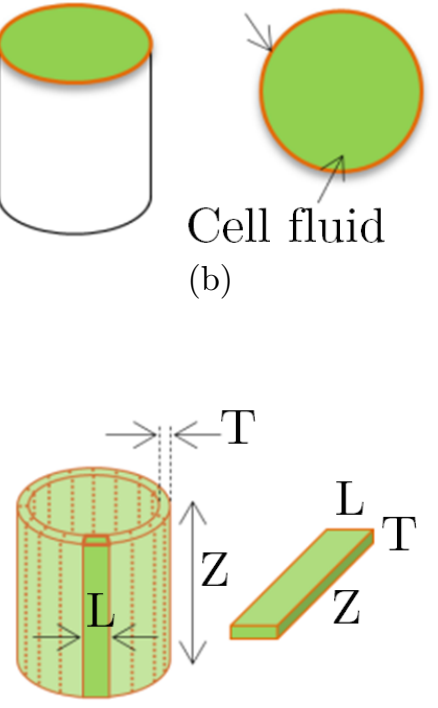

(d)

Figure 1: (a) A plant tissue simply represented as an aggregate of cylindrical cells; (b) a 2D model to represent any cylindrical cell; (c) particle scheme used for the 2D cell model: fluid model based on SPH particles and wall model based on DEM particles; and (d) discrete elements of the cell wall.

\subsection{Cell wall model}

As well as the basic cell wall model features introduced by Karunasena et al. [19], two additional features are used for the cell model: cell wall contractions and moisture removal during drying [20]. The cell wall is first discretised into a set of interconnected elements, as shown in Figure 1(d). Then, each of these elements is represented by a particle that has the physical properties of the wall element. A chain of such particles represents the complete cell wall, where cell wall deformations are referred to as particle displacements. As seen in Figure 2, the wall model involves seven types of 


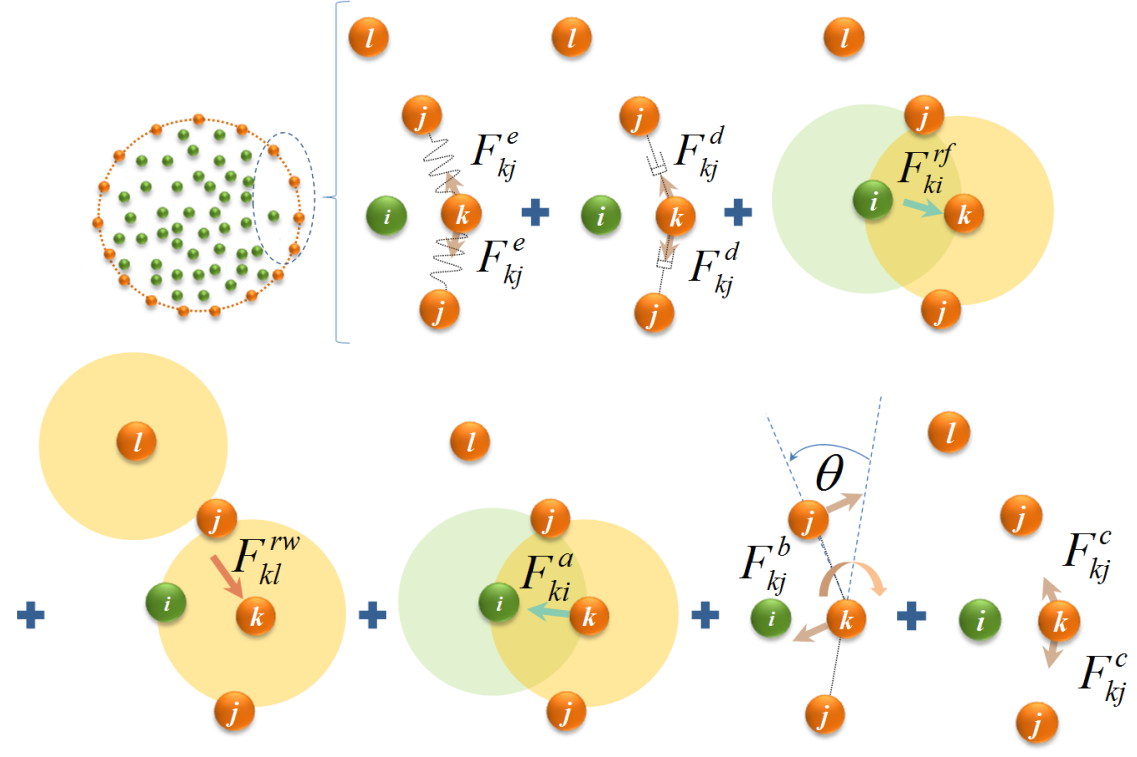

Figure 2: Force interactions of the DEM-based cell wall model: wall stiff forces $F_{k j}^{e}$, wall damping forces $F_{k j}^{d}$, wall-fluid repulsion forces $F_{k i}^{r f}$, non-bonded wall-wall repulsion forces $F_{k l}^{r w}$, wall-fluid attraction forces $F_{k i}^{a}$, forces due to wall bending stiffness $F_{k j}^{b}$ and forces for cell wall contractions during drying $F_{k j}^{c}$. Here, $\boldsymbol{i}$ represents fluid particles and $\mathfrak{j}, k, l$ represent wall particles.

force interactions: cell wall stiff forces $\mathrm{F}^{e}$, wall damping forces $\mathrm{F}^{\mathrm{d}}$, wall-fluid repulsion forces $\mathrm{F}^{\mathrm{rf}}$, non-bonded wall-wall repulsion forces $\mathrm{F}^{\mathrm{rw}}$, wall-fluid attraction forces $\mathrm{F}^{\mathrm{a}}$, forces due to the bending stiffness of the wall $\mathrm{F}^{\mathrm{b}}$, and cell wall contraction forces $F^{c}$. The total force on any wall particle $k$ is

$$
F_{k}=F_{k j}^{e}+F_{k j}^{d}+F_{k i}^{r f}+F_{k l}^{r w}+F_{k i}^{a}+F_{k j}^{b}+F_{k j}^{c},
$$

where $i$ is any neighbouring fluid particle, $j$ is any bonded wall particle and $l$ is any non-bonded wall particle. Detailed formulae for all forces were derived by Karunasena et al. [19, 20], and the details are not included here. Furthermore, Karunasena et al. [20] hypothesized that cell wall mass proportionately reduces along with the cell fluid mass during drying. When simulating drying cells, 


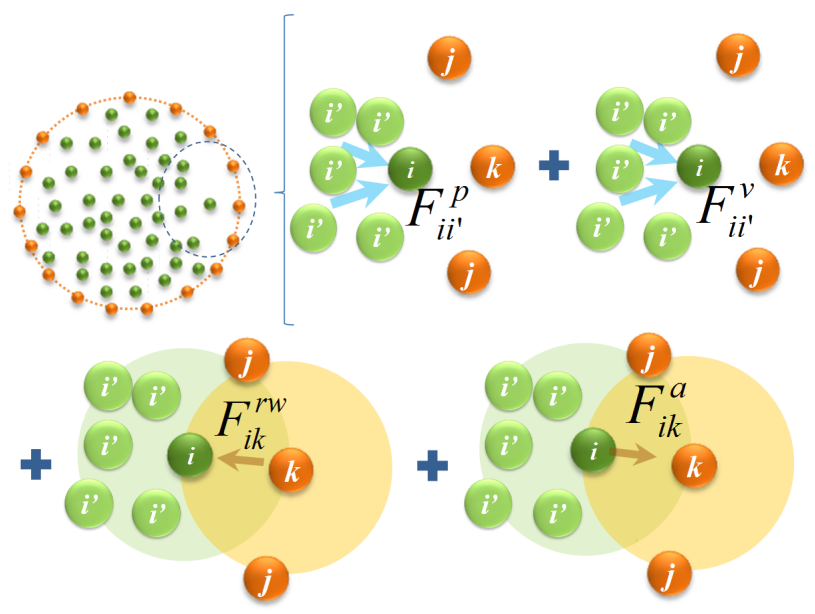

Figure 3: The cell fluid model uses four types of force interactions within the SPH particle scheme: pressure forces $F_{\mathfrak{i i}^{\prime}}^{p}$, viscous forces $F_{\mathfrak{i i}^{\prime}}^{v}$, wall-fluid repulsion forces $F_{i k}^{r w}$ and wall-fluid attraction forces $F_{i k}^{a}$. Here, $i, i^{\prime}$ represent fluid particles and $j, k$ represent wall particles.

cell wall mass is set proportional to the normalised moisture content of the fresh cell and is constant over time.

\subsection{Cell fluid model}

Since cell fluid is mainly a water-based solution, SPH is used to numerically model the cell fluid by treating it as a high viscous incompressible Newtonian fluid with low Reynolds number flow characteristics [15, 16]. We use a similar cell fluid model to that of Karunasena et al. [19, 20], involving four types of force interactions: fluid pressure forces $\mathrm{F}^{\mathrm{p}}$, fluid viscous forces $\mathrm{F}^{v}$, wall-fluid repulsion forces $\mathrm{F}^{\mathrm{rw}}$ and wall-fluid attraction forces $\mathrm{F}^{\mathrm{a}}$ (see Figure 3). The resultant effect of these forces gives the total force on any fluid particle $i$ as influenced by the neighbouring fluid particles $i^{\prime}$ and wall particles $k$ :

$$
F_{i}=F_{i i^{\prime}}^{p}+F_{i i^{\prime}}^{v}+F_{i k}^{r w}+F_{i k}^{a} .
$$




\subsection{Tissue generation}

A basic tissue model is introduced which consists of seven cells and our objective is to introduce the fundamental tissue model behaviour during drying, rather than focusing on the complexities of bulk tissue. However, this fundamental tissue arrangement can be used as a step in developing larger tissue structures by aggregation. Following the tissue generation approach introduced by Van Liedekerke et al. [16], a set of individual cells are initiated as squares and aggregated into a simplified tissue structure (see Figure 6(a)) by maintaining a fixed initial gap between them. The model accounts for the key physical property of the middle lamella (composed of pectin): its stiffness. Accordingly, the adjacent wall particles are linked by one-to-one linear spring force interactions

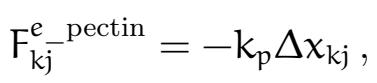

where $k$ and $j$ are adjacent wall particles of any two cells, $k_{p}$ is the stiffness of the pectin layer (see Table 1 ) which was selected after several trial simulations. The $\Delta \mathrm{x}_{\mathrm{kj}}$ is the change in the distance between particle $\mathrm{k}$ and $\boldsymbol{j}$, compared to the initial pectin layer thickness (see Table 1). Further, to avoid overlapping of cells, repulsion forces act between the cell wall particles, defined as LJ force interactions [19], with a contact strength of $f_{k j}^{r c}$ :

$$
F_{k j}^{r c}=\sum_{j} f_{k j}^{r c} x_{k j} .
$$

This wall particle-based cell-cell interaction model is computationally much more efficient than the fluid particle based method proposed by Van Liedekerke et al. $[15,16]$, since there are fewer neighbouring particle pairs.

\subsection{Computational setup and validation}

This model was firstly used by Karunasena et al. [20] to model a fresh cell and Table 1 shows the values used for key model parameters and physical properties. For a dried cell Karunasena et al. [19] used a moisture-content-domain 
Table 1: Key parameter values used to model a fresh apple tissue

Parameter

Initial cell diameter $\left(\mathrm{D}_{0}\right)$

Initial cell height $\left(Z_{0}\right)$

Wall initial thickness $\left(T_{0}\right)$

Initial cell fluid mass

Initial cell wall mass $(10 \%$ of cell fluid mass)

Fluid viscosity $(\mu)$

Initial fluid density $\left(\rho_{0}\right)$

Fresh cell turgor pressure $\left(\mathrm{P}_{\mathrm{T}}\right)$

Fresh cell osmotic potential $(\Pi)$

Wall permeability $\left(\mathrm{L}_{\mathrm{P}}\right)$

Wall shear modulus $(G)$

Wall bending stiffness $\left(k_{b}\right)$

Wall damping ratio $(\gamma)$

Fluid compression modulus (K)

Wall contraction force coefficient $\left(k_{w c}\right)$

Empirical factors on cell wall contractions $(a, b)$

LJ contact strength for wall-fluid repul- $1 \times 10^{-12} \mathrm{~N} \mathrm{~m}^{-1}$ sions $\left(f_{0}^{\text {rf }}\right)$

LJ contact strength for wall-wall repul- $1 \times 10^{-12} \mathrm{~N} \mathrm{~m}^{-1}$ set sions $\left(f_{0}^{r w}\right)$

LJ contact strength for wall-fluid at- $2 \times 10^{-12} \mathrm{~N} \mathrm{~m}^{-1}$ tractions $\left(f_{0}^{a}\right)$

LJ contact strength for cell-cell repul- $1 \times 10^{-12} \mathrm{~N} \mathrm{~m}^{-1}$ sions $\left(f_{0}^{r c}\right)$

Pectin layer stiffness $\left(k_{p}\right)$

Pectin layer thickness $\left(T_{p}\right)$

$1 \mathrm{~N} \mathrm{~m}^{-1}$

$5 \mu \mathrm{m}$

Initial smoothing length $\left(h_{0}\right)$, nor- 1.3

malised by initial fluid grid spacing

Time step $(\Delta \mathrm{t})$

$0.1 \mathrm{Pas}$

$1000 \mathrm{~kg} \mathrm{~m}^{-3}$

$200 \mathrm{kPa}$

$-200 \mathrm{kPa}$

$2.5 \times 10^{-6} \mathrm{~m}^{2} \mathrm{~N}^{-1} \mathrm{~s}$

$18 \mathrm{MPa}$

$1 \times 10^{-10} \mathrm{~N} \mathrm{~m} \mathrm{rad}^{-1}$

$5 \times 10^{-6} \mathrm{~N} \mathrm{~m}^{-1} \mathrm{~S}$

$20 \mathrm{MPa}$

$4 \times 10^{4} \mathrm{~N} \mathrm{~m}^{-1}$

$0.2,0.9$ 
based approach rather than a conventional time-domain based approach. Additionally, Karunasena et al. [20] hypothesized that turgor pressure remains positive throughout the drying cycle and gradually decreases with the reduction of the cell fluid mass. Therefore, the turgor pressure is simply taken to be proportional to the moisture content of the dried cell. Accordingly, with a fresh cell turgor pressure of $200 \mathrm{kPa}$ and normalised fresh cell moisture content $X / X_{0}=1.0$, the dried cells with normalised moisture content $0.8,0.6$, $0.4,0.3$ and 0.2 were simulated by using initial turgor pressures of $160 \mathrm{kPa}$, $120 \mathrm{kPa}, 80 \mathrm{kPa}, 60 \mathrm{kPa}$ and $40 \mathrm{kPa}$. The magnitude of the osmotic potential is set equal to the initial turgor pressure in each case and is constant over time $[19,20]$. In each case, we set the initial cell wall mass to $0.8,0.6,0.4$, 0.3 and 0.2 , normalised by the the fresh cell wall mass (which is $10 \%$ of the fresh cell fluid mass as given in Table 1) [20]. In each case, the cell wall mass is fixed over time.

At the final time, the final cell properties characterise each of the dried cell states. The steady state cellular deformations are quantified using several cellular geometrical parameters such as cell area $A$, feret diameter $D=\sqrt{4 A / \pi}$, cell perimeter $P$, cell roundness $R=4 \pi A / P^{2}$, cell elongation $\mathrm{EL}=\sqrt{4 \mathrm{~A} / \pi} /($ major axis length) and cell compactness $\mathrm{C}=$ (major axis length)/(minor axis length). These parameters are analysed against the dry basis moisture content $X=m_{\text {water }} / m_{\text {dry-solid }}$ for mass $m$. For better comparison, normalized parameters are defined: $X / X_{0}, A / A_{0}$, $\mathrm{D} / \mathrm{D}_{0}, \mathrm{P} / \mathrm{P}_{0}, \mathrm{R} / \mathrm{R}_{0}, \mathrm{EL} / \mathrm{EL}_{0}$ and $\mathrm{C} / \mathrm{C}_{0}$ by dividing each parameter by the corresponding initial value of the fresh cell: $X_{0}, A_{0}, D_{0}, P_{0}, R_{0}, E L_{0}$ and $C_{0}$. These simulation results are compared with apple cellular experimental data obtained by Karunasena et al. [21] and Mayor et al. [5].

\subsection{Computer implementation and visualization}

The model was programmed in parallel $\mathrm{C}++$ and simulations were run on a high performance computer HPC using six cores (each a $2.66 \mathrm{GHz}$ processor 
and 256 GB RAM) on a single Xeon E5-2670 node. The $\mathrm{C}++$ source code was developed from an existing SPH source code written in Fortran [10]. Open Visualization Tool (OVITO) [22] is used to visualise results.

\section{Results and discussion}

\subsection{Selection of an optimal particle scheme}

Several trial simulations were conducted to select an appropriate particle scheme for the single cell model which optimizes the computational accuracy while minimizing the computational cost (CPU time). In this regard, the main factors involved are the particle resolution [19], influence domain particle number $[10,23,19]$ and the initial relative locations of boundary and interior particles [23, 19]. Here, the computational accuracy of the cylindrical cell model is defined in terms of the model consistency error which was defined by Van Liedekerke et al. in their SPH-DEM cell model [16]. For moderate model resolutions, the optimum number of cell wall particles $n_{w}=100$ to minimize the model consistency error at a moderate computational cost [19]. Then the corresponding fluid particle number $n_{f}=784$ to ensure an equally spaced initial particle placement.

Using the optimized particle resolution for $n_{w}$ and $n_{f}$ a series of secondary tests were conducted to further optimize the computational accuracy of the model. This is done by changing the influence domain particle number and $\varepsilon_{0} / x_{0}$, which is the ratio of the minimum initial relative distance between the outer most fluid particles and the cell wall particles $\varepsilon_{0}$, and the initial fluid particle spacing $x_{0}$. It was found that when the influence domain particle number is maintained around 20 and $\varepsilon_{0} / x_{0} \leqslant 0.2$, the accuracy is optimized [19]. The selected influence domain particle number is fairly agreeable with the standard SPH recommendations to ensure higher accuracy of $2 \mathrm{D}$ models [10]. Also, $\varepsilon_{0} / x_{0}$ agrees with the values reported for $2 \mathrm{D}$ heat 


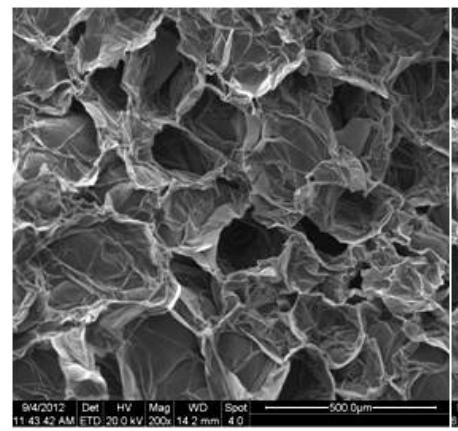

(a)

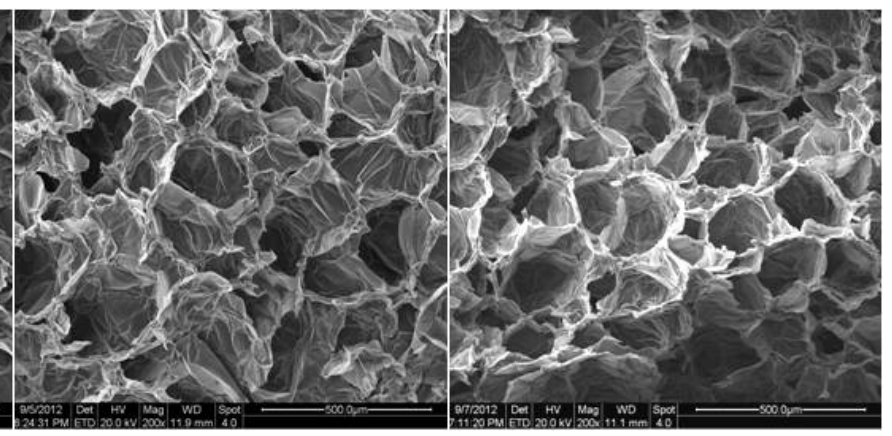

(b)

(c)

Figure 4: SEM images of apple tissues at different states of dryness: (a) $X / X_{0}=$ 1.0 (fresh), (b) $X / X_{0}=0.5$, and (c) $X / X_{0}=0.2$.

conduction modelling using SPH [23]. This optimized particle scheme produces a minimum percentage error of model consistency of about $1 \%$ which compares favourably with state of the art SPH-DEM cell models that normally have $4 \%$ to $7 \%$ consistency errors [16]. Fluid incompressibility is maintained during the simulations by limiting the density fluctuations to $0.02 \%$.

\subsection{SEM image analysis of dried tissue samples}

Figure 4 shows selected SEM images of apple tissue. In fresh tissue, as seen in Figure 4(a), the majority of the cells are quite similar in size and appear to be fairly circular. This is due to the positive turgor pressure in the cell fluid, which is counterbalanced by the cell wall tension [8,24]. Since cells are bonded to the surrounding cells in the tissue; there are considerable cell wall wrinkles and warps. As the tissue dries, there is significant microstructural deformation, as seen in Figure 4(b) and (c). These deformations are mainly driven by the moisture removal from the cell interior, turgor loss and cell wall contractions. At the same time, these microscale deformations are restrained to a small degree by the rigidity of the cell walls. The cell walls usually 


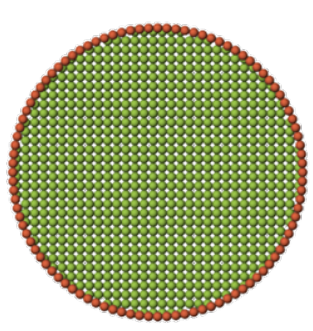

(a)

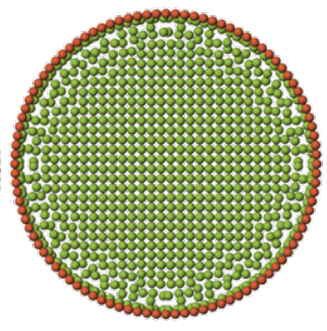

(b)

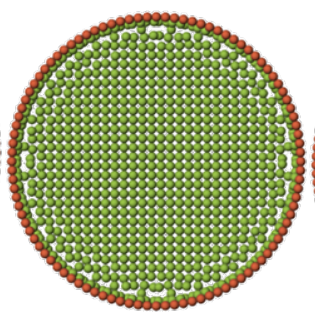

(c)

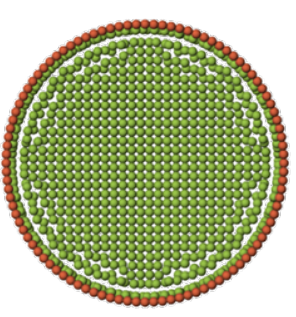

(d)

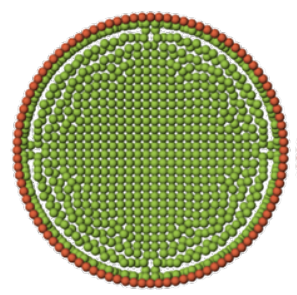

(e)

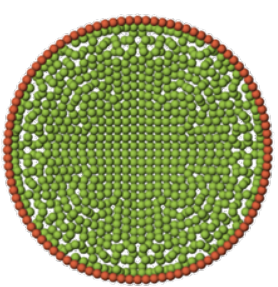

(f)

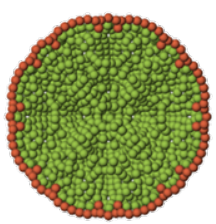

(g)

Figure 5: Single cell model with (a) initial particle placement before simulations, (b) turgid condition $\mathrm{X} / \mathrm{X}_{0}=1.0, \mathrm{P}_{\mathrm{T}}=200 \mathrm{kPa}$, dried conditions: (c) $\mathrm{X} / \mathrm{X}_{0}=0.8, \mathrm{P}_{\mathrm{T}}=160 \mathrm{kPa}$, (d) $\mathrm{X} / \mathrm{X}_{0}=0.6, \mathrm{P}_{\mathrm{T}}=120 \mathrm{kPa}$, (e) $\mathrm{X} / \mathrm{X}_{0}=0.4$, $\mathrm{P}_{\mathrm{T}}=80 \mathrm{kPa}$, (f) $\mathrm{X} / \mathrm{X}_{0}=0.3, \mathrm{P}_{\mathrm{T}}=60 \mathrm{kPa}$, and $(\mathrm{g}) \mathrm{X} / \mathrm{X}_{0}=0.2, \mathrm{P}_{\mathrm{T}}=40 \mathrm{kPa}$.

undergo irregular deformations during drying but with minimum damage to the structural integrity (Figure 4(c)).

\subsection{Simulation of cellular deformations}

As described in Section 2.5, different dried cell states characterised by the normalized moisture content and turgor pressure were simulated starting from a fresh cell state $X / X_{0}=1.0$ and $P_{\mathrm{T}}=200 \mathrm{kPa}$ to an extremely dry cell state $\left(X / X_{0}=0.2\right.$ and $\left.P_{\mathrm{T}}=40 \mathrm{kPa}\right)$. Single cell based simulation results are presented in Figure 5 and tissue based results are presented in Figure 6. 


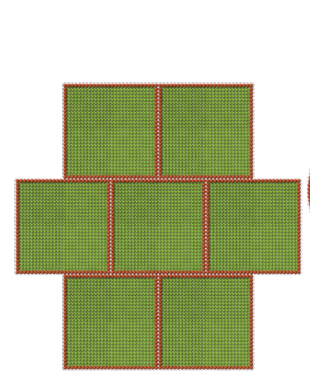

(a)

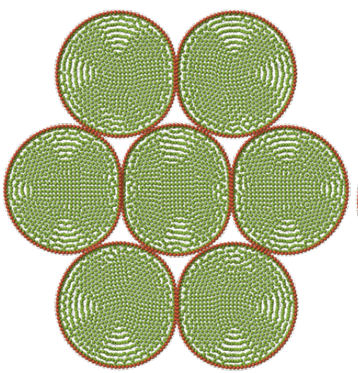

(b)

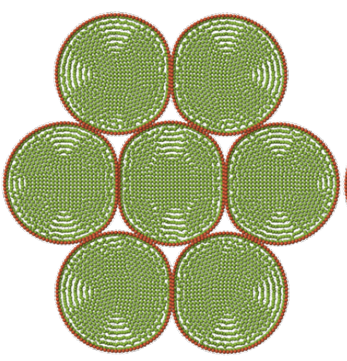

(c)

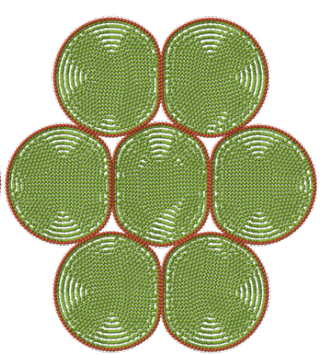

(d)

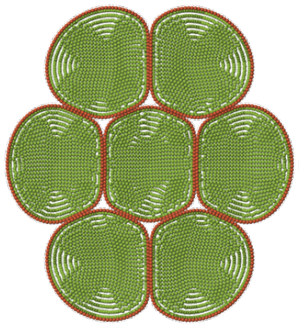

(e)

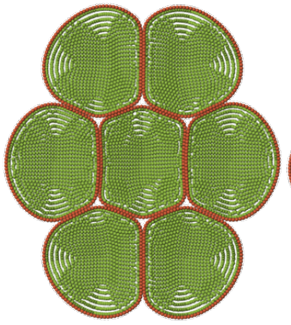

(f)

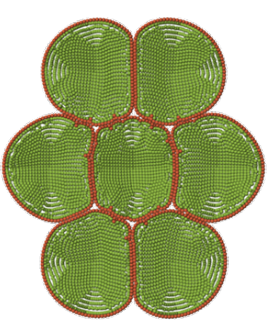

(g)

Figure 6: Tissue model with (a) initial particle placement before simulations, (b) turgid condition $X / X_{0}=1.0, P_{\mathrm{T}}=200 \mathrm{kPa}$, dried conditions: (c) $X / X_{0}=$ $0.8, \mathrm{P}_{\mathrm{T}}=160 \mathrm{kPa}$, (d) $\mathrm{X} / \mathrm{X}_{0}=0.6, \mathrm{P}_{\mathrm{T}}=120 \mathrm{kPa}$, (e) $\mathrm{X} / \mathrm{X}_{0}=0.4, \mathrm{P}_{\mathrm{T}}=$ $80 \mathrm{kPa}$, (f) $\mathrm{X} / \mathrm{X}_{0}=0.3, \mathrm{P}_{\mathrm{T}}=60 \mathrm{kPa}$, and (g) $\mathrm{X} / \mathrm{X}_{0}=0.2, \mathrm{P}_{\mathrm{T}}=40 \mathrm{kPa}$.

Compared to the initial particle placement (Figure 5(a)), the fresh cell inflates, resembling a turgid cell in actual tissues (Figure 5(b)). Further, the dried cell states clearly indicate a gradual shrinkage as drying progresses. At the latter part of the drying cycle, the cells experience some degree of cell wall warping (see Figure 5(g)) which agrees with the experiments (Figure 4(b) and (c)).

In the case of tissue simulations, the same moisture content and turgor pressure values were used. Figure 6(a) shows fresh tissue and the dried tissue states are shown in Figure 6(c)-(g). Here we mainly focus on the central cell of each tissue which fairly represents any general cell within realistic tissue that 
is fully bonded to surrounding cells. It is evident that the shrinkage and cell wall warping behaviour observed in the single cell simulations is observed in the tissue simulations as well. Further, compared to the single cell simulations, the central cell of the tissue is less circular and the deformations are restrained by the intercellular interactions. This is clearly observed when the extremely dry single cell state (Figure $5(\mathrm{~g})$ ) is compared with the corresponding tissue case (Figure $6(\mathrm{~g})$ ).

To study drying effects in detail, several cellular geometrical parameters are analysed, as presented in Figure 7. For tissue results, only the central cell is used for parameter calculations. It is clear that both the single cell model and the tissue model closely replicate the shrinkage behaviour of real tissue during drying, especially when the primary cell geometric properties such as cell area, diameter and perimeter are considered (Figure 7(a)-(c)). Further, in the case of extremely dry cell states, the tissue model describes a controlled shrinkage behaviour compared to the single cell model. This is mainly due to the influence of intercellular bonds in the tissue model which resist cellular deformations. For derived cellular parameters such as roundness, elongation and compactness (Figure $7(\mathrm{~d})-(\mathrm{f})$ ), a fairly good agreement is observed. However, for the $A / A_{0}, D / D_{0}$ and $R / R_{0}$ trends, especially for extremely dry cells, considerable deviations are observed which may be due to the limited number of cells used in the tissue model. Since observations show that that this simplified tissue model is far better than the single cell model, the predictions could probably be further improved if larger tissues with many cells are modelled, thus describing more realistic cell interactions.

\subsection{Model sensitivity to the force coefficient of cell wall contractions}

Cell wall contraction is one of the key factors influencing cellular deformations. Four different $k_{w c}$ values are considered and compared with the original fully functional model both qualitatively (Figure 8) and quantitatively (Figure 9). 


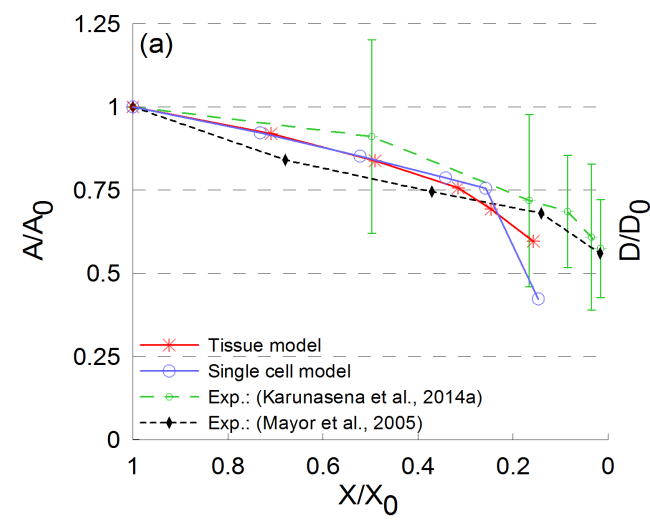

(b)

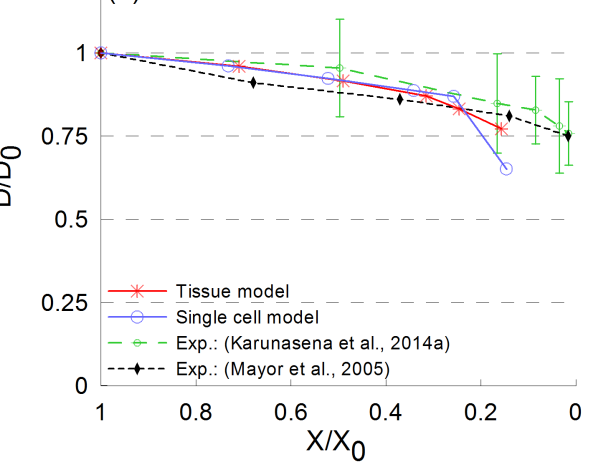

1.25 (c)

1.6

(d)
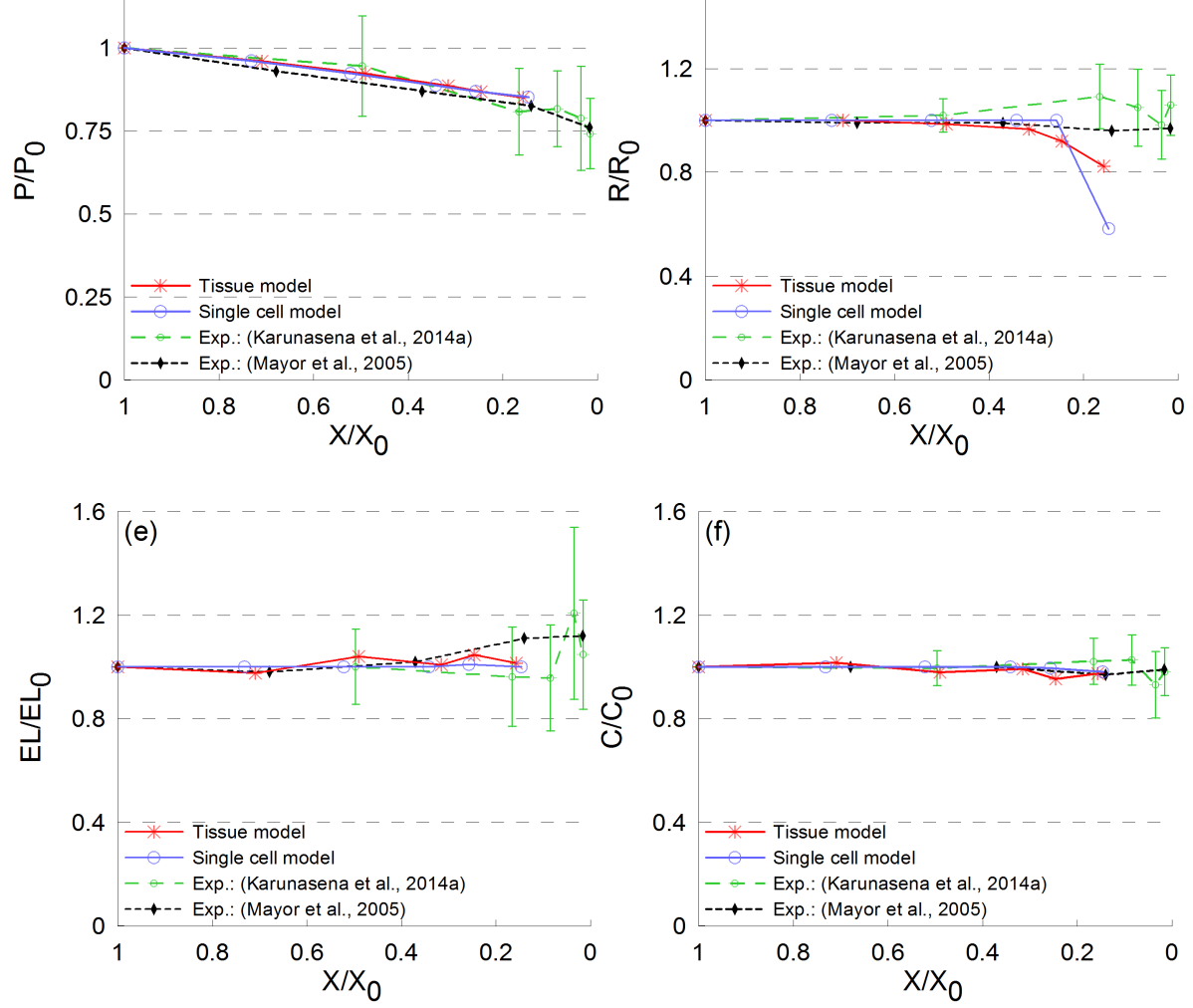

Figure 7: Variation during drying of (a) $A / A_{0}$, (b) $D / D_{0}$, (c) $P / P_{0}$, , d) $R / R_{0}$, (e) $\mathrm{EL} / \mathrm{EL}_{0}$, and (f) $\mathrm{C} / \mathrm{C}_{0}$. Error bars indicate one standard deviation. 


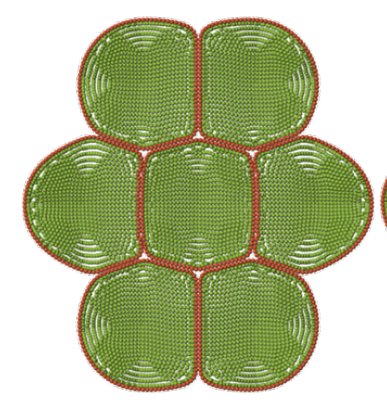

(a)

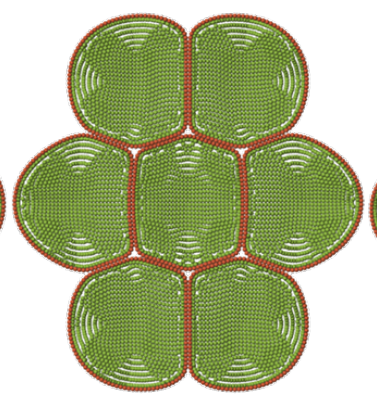

(b)

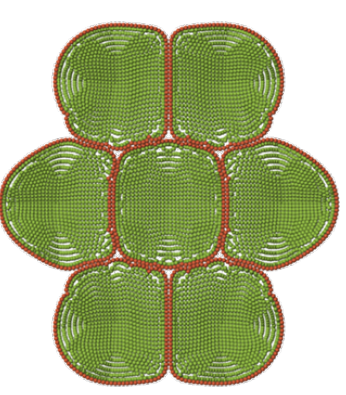

(c)

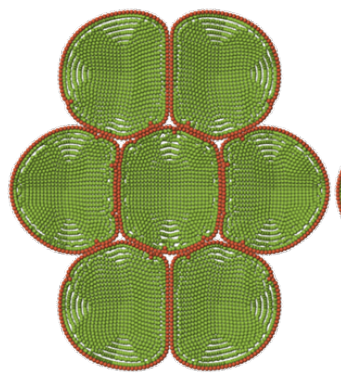

(d)

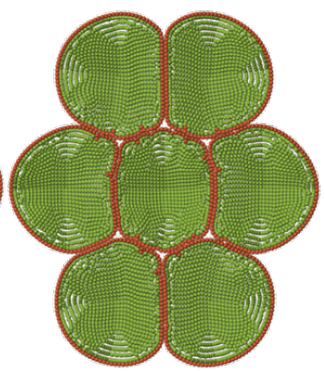

(e)

Figure 8: Simulated dried tissues at $X / X_{0}=0.2$ with different force coefficients of cell wall contractions $k_{w c}$ : (a) $0.05 k_{w c 0}$, (b) $0.1 k_{w c 0}$, (c) $0.5 k_{w c 0}$, (d) $k_{w c 0}$, and (e) $1.5 k_{w c 0}$, where $k_{w c 0}=4 \times 10^{4} \mathrm{~N} \mathrm{~m}^{-1}$.

When lower $k_{w c}$ values are used (Figure $8(a)-(b)$ ), the cells in the tissue are fairly circular even when extremely dry. When $k_{w c}$ is gradually increased (Figure 8(c)-(e)), cells experience a higher degree of local wrinkling and shrinkage. These trends are further evident from the quantitative results presented in Figure 9. Considering the primary geometric parameters, as presented in Figure 9(a)-(c), it is observed that $\boldsymbol{k}_{w c}$ should be large to have good agreement with the experiments. However, the influence of $k_{w c}$ on derived shape parameters such as $R / R_{0}, E L / E L_{0}$ and $C / C_{0}$ is comparatively lower, which is mainly due to the cancellation of similar effects when calculating 


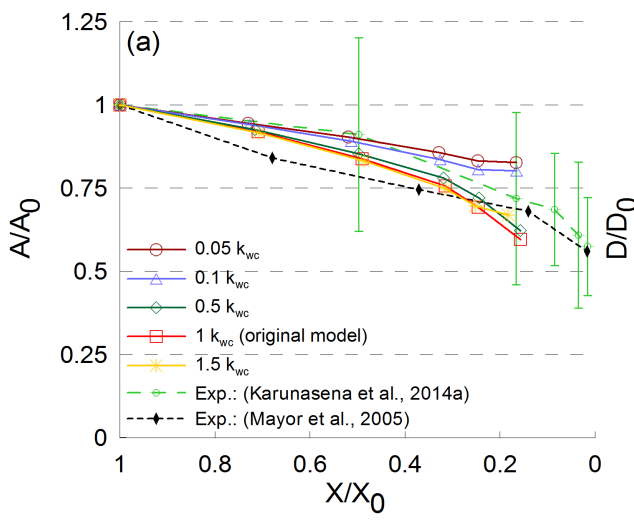

1.25 (b)

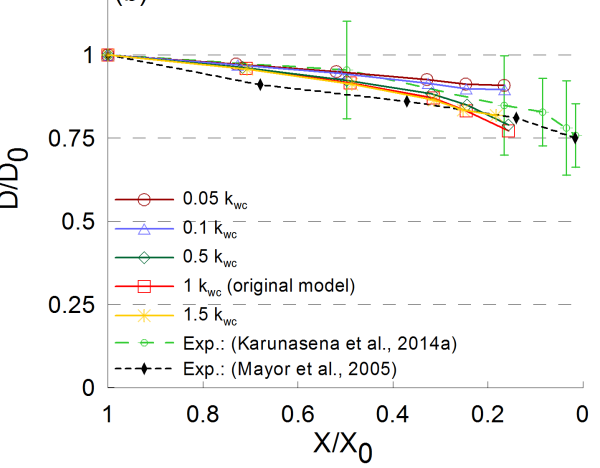

1.25

(c)

1.6

(d)
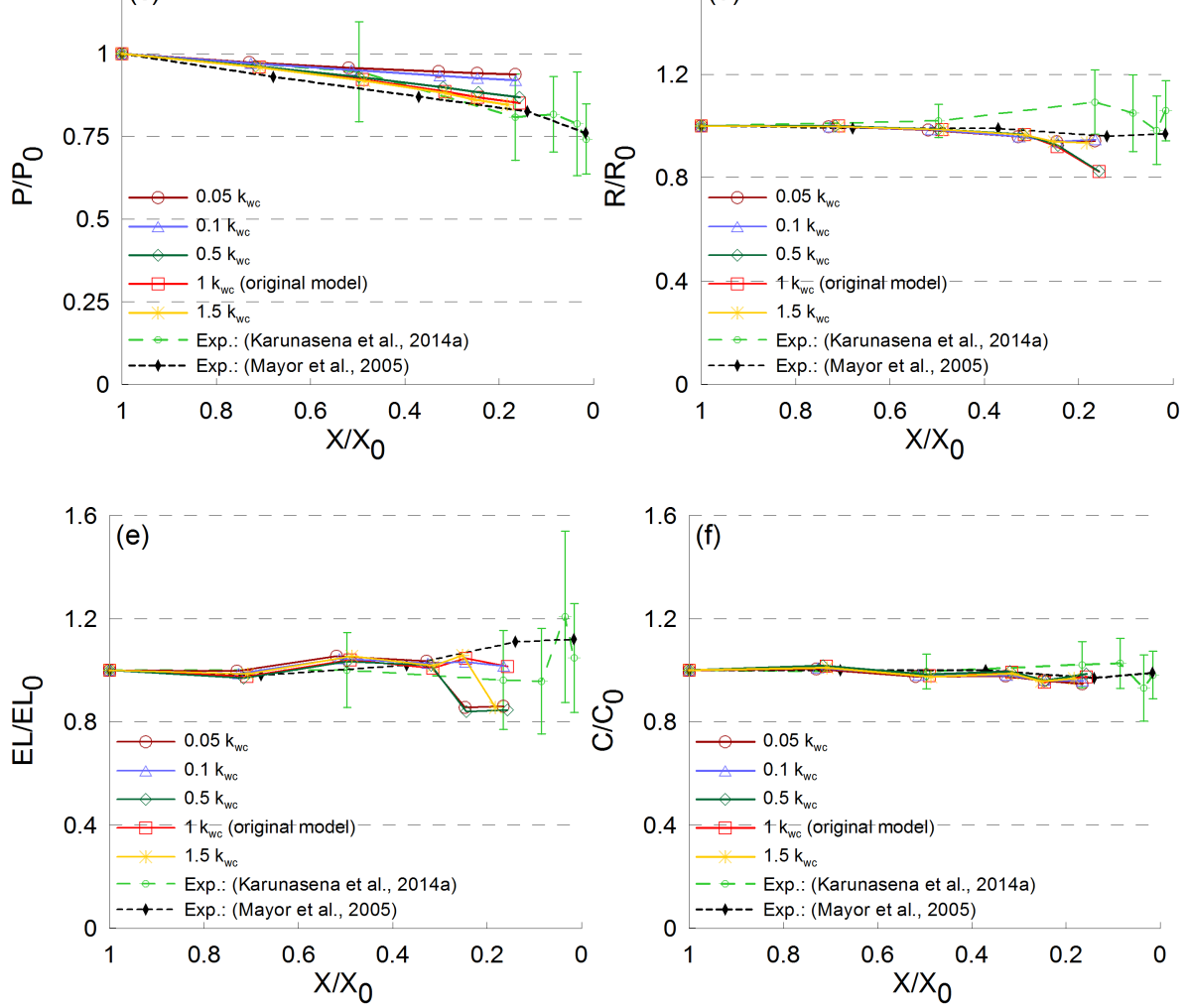

Figure 9: Effect of force coefficient of cell wall contractions $k_{w c}$ on (a) $A / A_{0}$, (b) $\mathrm{D} / \mathrm{D}_{0}$, (c) $\mathrm{P} / \mathrm{P}_{0}$, (d) $\mathrm{R} / \mathrm{R}_{0}$, (e) $\mathrm{EL} / \mathrm{EL}_{0}$, and (f) $\mathrm{C} / \mathrm{C}_{0}$. 


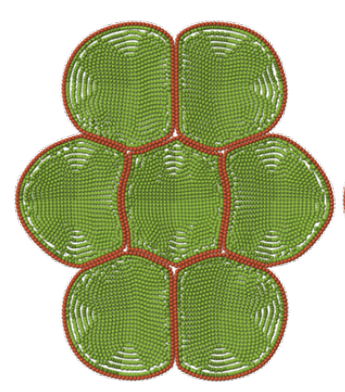

(a)

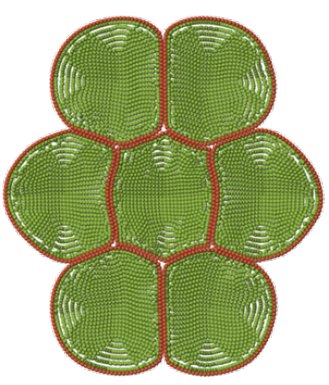

(b)

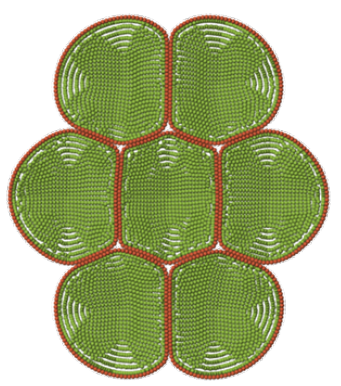

(c)

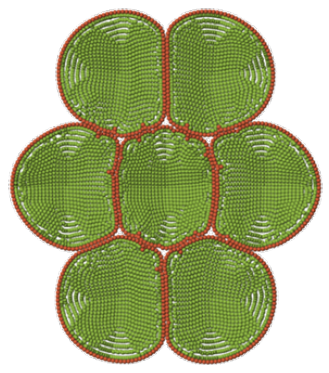

(d)

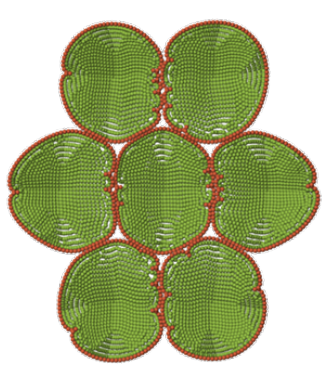

(e)

Figure 10: Simulated dried tissues at $X / X_{0}=0.2$ with different cell wall bending stiffness $k_{b}$ : (a) $0.001 k_{b 0}$, (b) $0.01 k_{b 0}$, (c) $0.1 k_{b 0}$, (d) $k_{b 0}$, and (e) $10 k_{b 0}$, where $k_{b 0}=1 \times 10^{-10} \mathrm{~N} \mathrm{~m} \mathrm{rad}^{-1}$.

such normalized parameters (Figure 9(d)-(f)).

\subsection{Model sensitivity to the cell wall bending stiffness}

The cell wall bending stiffness $k_{b}$ is also a key parameter that influences cell wall deformations and wrinkling. Four different $k_{b}$ values with different orders of magnitude were tested and qualitative results are presented in Figure 10. Compared to the original cell model presented in Figure 10(d), lower $k_{b}$ values (Figure 10(a) and (b)) result in large-scale cell wall bends compared 


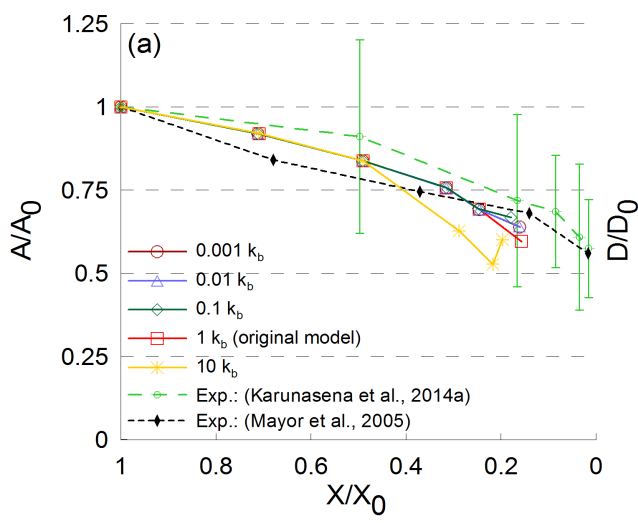

(b)

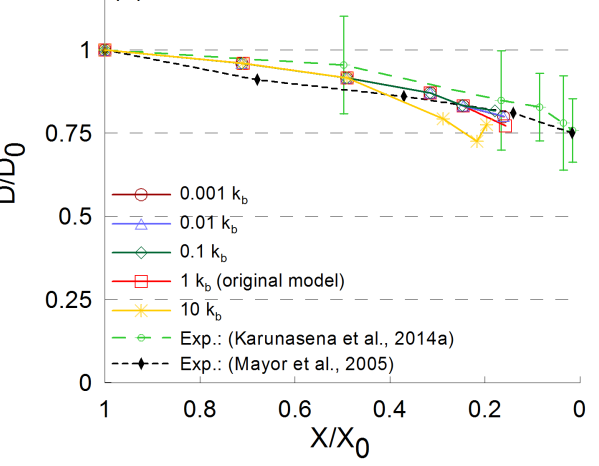

1.25 (c)

1.6 (d)
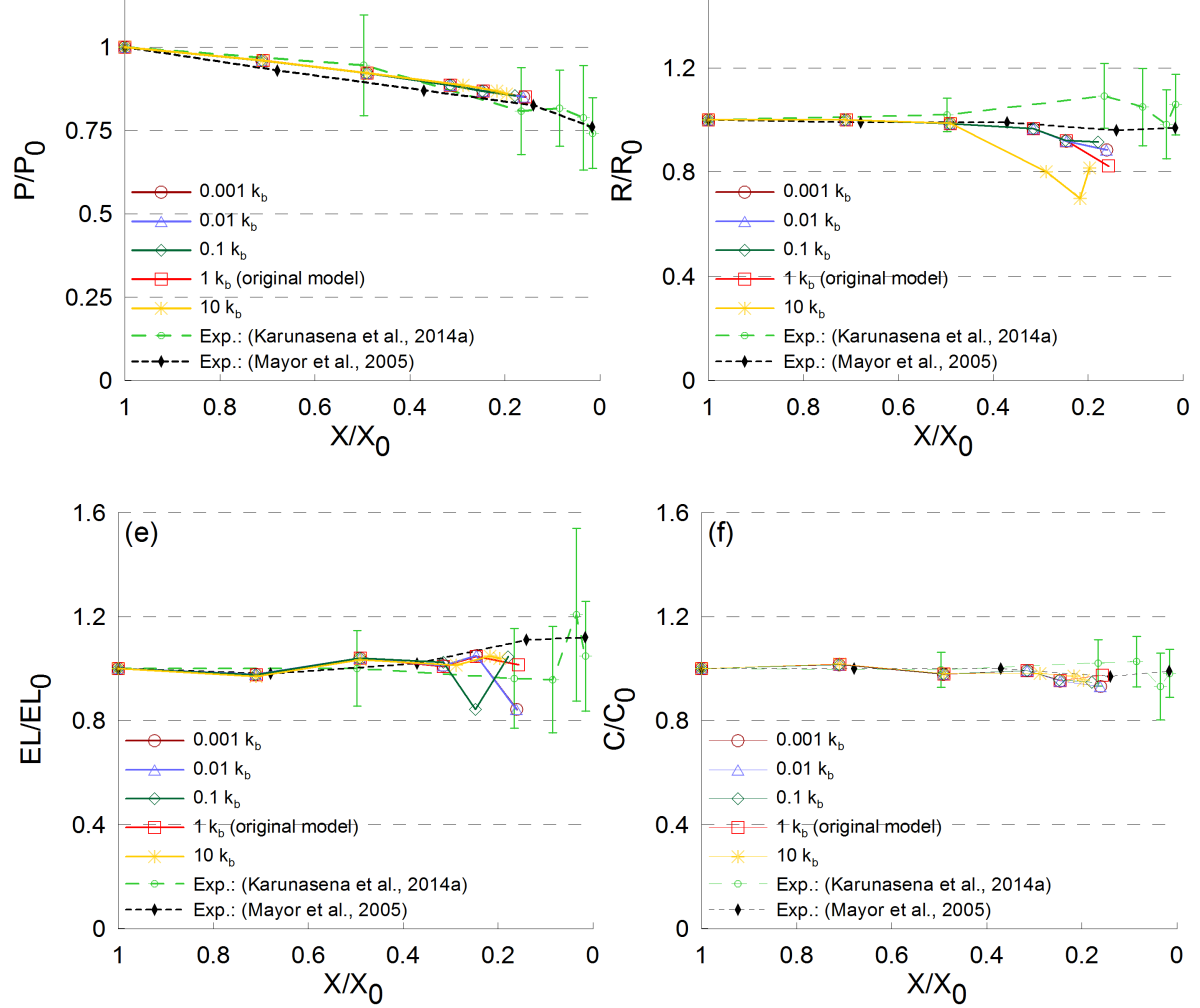

Figure 11: Effect of cell wall bending stiffness $k_{b}$ on (a) $A / A_{0}$, (b) $D / D_{0}$, (c) $\mathrm{P} / \mathrm{P}_{0}$, (d) $\mathrm{R} / \mathrm{R}_{0}$, (e) EL/EL, and (f) $\mathrm{C} / \mathrm{C}_{0}$. 


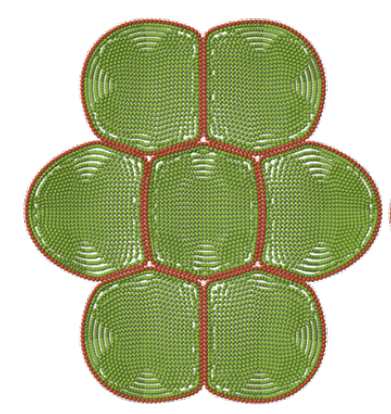

(a)

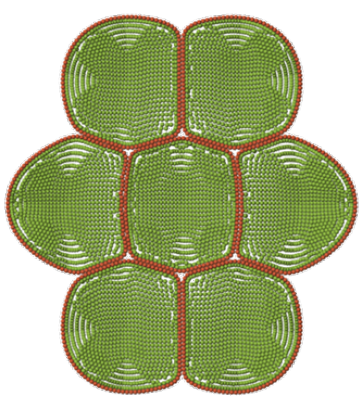

(b)

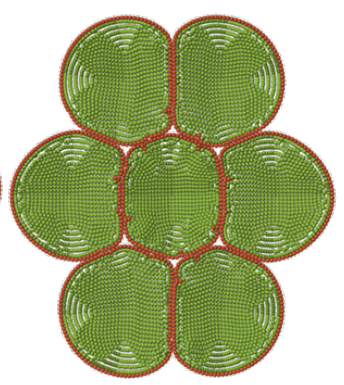

(c)

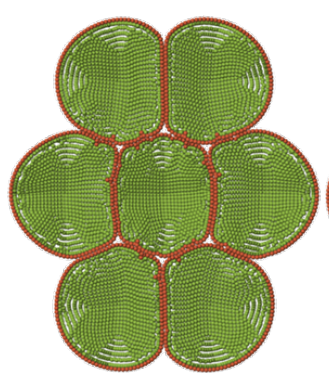

(d)

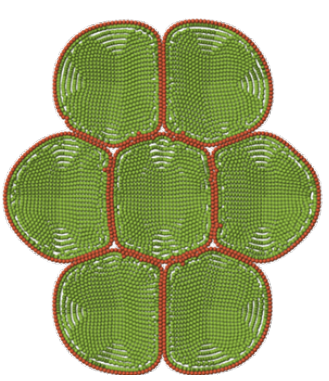

(e)

Figure 12: Simulated dried tissues at $X / X_{0}=0.2$ with different cell wall

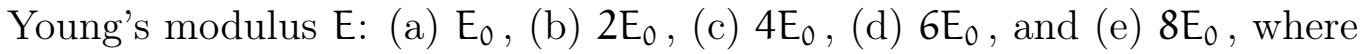
$\mathrm{E}_{0}=54 \mathrm{MPa}$.

to of moderate $k_{b}$ values (Figure 10(c)). This indicates that lower $k_{b}$ values result in flexible cell walls. However, higher $k_{b}$ values tend to cause higher local wrinkling or warping effects resembling the warped cell walls observed in experiments (Figure 4(b)-(c)). To elaborate these effects further, the normalized cellular geometrical parameters were analysed, as presented in Figure 11. The overall observation is that the curves with the three lowest $k_{b}$ values do not show any significant difference when compared with the original model. This indicates that, even though there are identifiable localized cell shape variations with lower $k_{b}$ values (Figure 10(a)-(c)), such difference are 


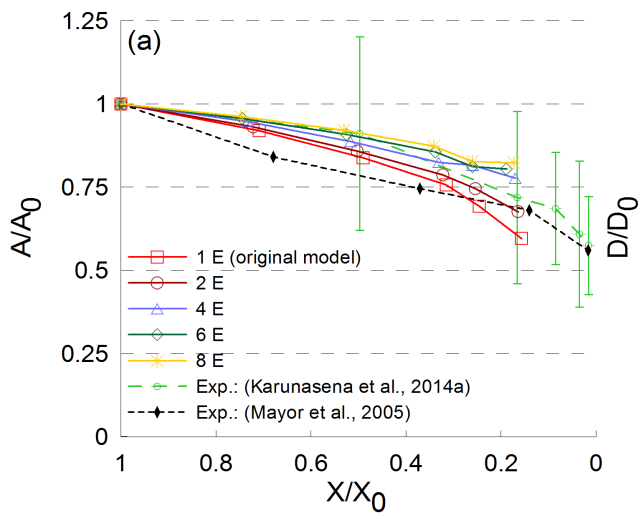

(b)

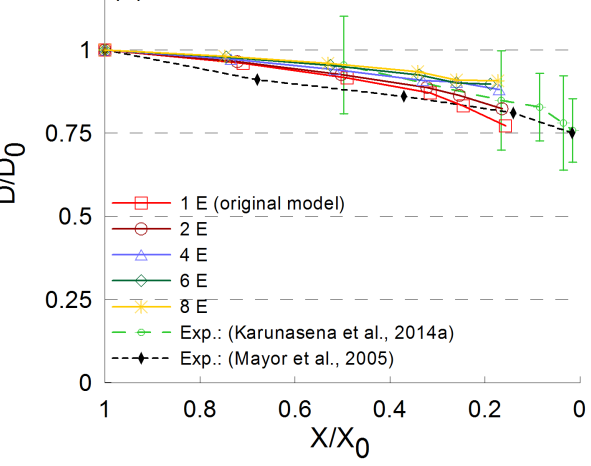

1.25

(c)

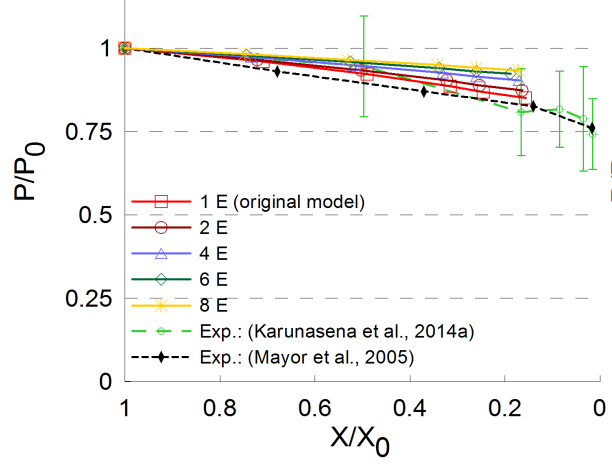

1.6

(d)
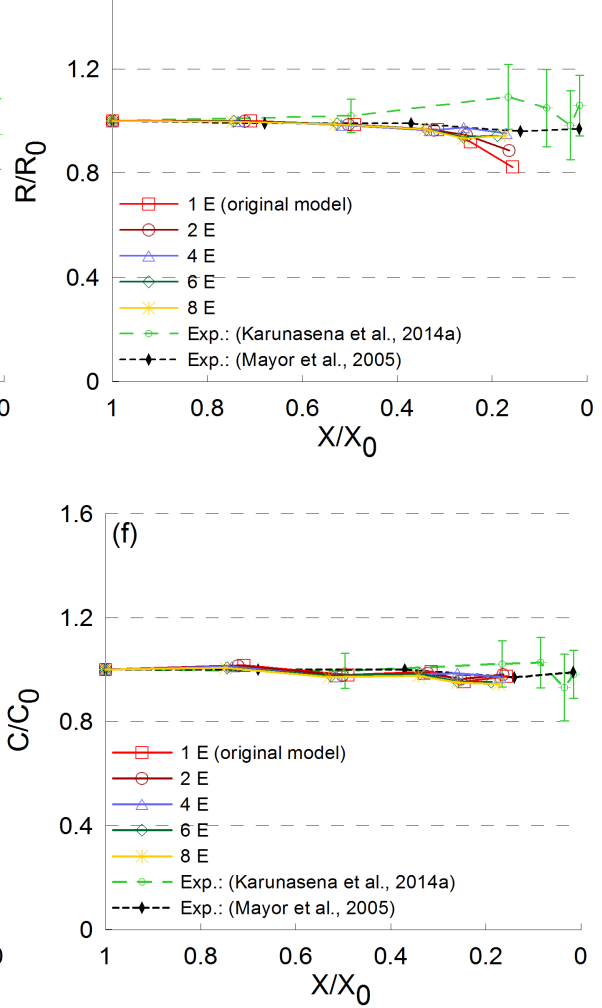

Figure 13: Effect of cell wall Young's modulus $E$ on (a) $A / A_{0}$, (b) $D / D_{0}$, (c) $\mathrm{P} / \mathrm{P}_{0}$, (d) $\mathrm{R} / \mathrm{R}_{0}$, (e) EL/EL 0 , and (f) $\mathrm{C} / \mathrm{C}_{0}$. 
not reflected in qualitative parameters, which could be due to normalization. However the largest $k_{b}$ curve indicates a fairly different trend which is due to excessive deformations caused by much higher bending forces. Further, in Figure 11(c), it is observed that the cell perimeter change is fairly independent of $k_{b}$. This is because the bending forces influenced by $k_{b}$ act perpendicular to the wall elements and do not cause any force influence along the wall elements to stretch or compress them tangential to the cell wall.

\subsection{Model sensitivity to the cell wall Young's modulus}

Cell wall Young's modulus $E$ variations directly influence any tensile or compressive responses of the cell wall. Here $G \approx E / 3$ was varied and predictions are presented in Figure 12 and Figure 13. In Figure 12, the cells that have stiffer cell walls tend to resist shrinkage and result in comparatively bigger dried cells. Also, there is a significant reduction of cell wall warping effects in stiffer cell walls. These effects are further evident in Figure 13, when primary cellular parameters such as $A / A_{0}, D / D_{0}$ and $P / P_{0}$ (Figure $13(a)-(c)$ ) are considered. However for derived parameters such as $R / R_{0}$ and $C / C_{0}$ (Figure 13(d) and Figure 13(f)), the influence of cell wall Young's modulus is not very evident. However, the $\mathrm{EL} / \mathrm{EL}_{0}$ trend indicates a considerable deviation for higher cell wall Young's modulus.

\section{Conclusion}

A mesh free based 2D tissue model was developed to simulate microscale deformations of plant cells during drying which can be used as a step in developing larger and more complex tissue models. A wide range of simulations were conducted and in most instances, a fairly good agreement was observed between experiments and model predictions. Compared to single cell models, tissue models produce limited shrinkage trends especially for cell 
area, feret diameter and roundness. Model predictions are quite sensitive to $k_{w c}, k_{b}$ and $E$. Lower $k_{w c}$ values or higher $k_{b}$ values result in increased local warping and wrinkling effects. Higher $E$ values tend to resist shrinkage. Therefore, a careful selection of these parameters is recommended to improve model predictions. The proposed method can be used to study different plant cell types and tissue varieties since the SPH-DEM scheme is fundamentally flexible for such improvements [25]. This model could eventually be used for numerical studies leading to product and process improvements in food engineering.

Acknowledgements The authors extend their thanks to the graduate student Ms. Parva Hesami of Queensland University of Technology (QUT), Brisbane, Australia for experimental contributions. Also the high performance computing facilities provided by QUT and the financial assistance provided by the International Postgraduate Research Scholarship, Australian Postgraduate Award and QUT are gratefully acknowledged. We also thank the support provided by the Faculty of Engineering, University of Ruhuna, Sri Lanka.

\section{References}

[1] S. V. Jangam. An overview of recent developments and some R\&D challenges related to drying of foods. Dry. Technol., 29(12):1343-1357, 2011. doi:10.1080/07373937.2011.594378 C112

[2] L. Mayor and A. M. Sereno. Modelling shrinkage during convective drying of food materials: a review. J. Food Eng., 61(3):373-386, 2004. doi:10.1016/s0260-8774(03)00144-4 C112

[3] M. S. Rahman, I. Al-Zakwani, and N. Guizani. Pore formation in apple during air-drying as a function of temperature: porosity and pore-size distribution. J. Sci. Food Agr., 85(6):979-989, 2005. doi:10.1002/jsfa.2056 C112 
[4] M. K. Bartlett, C. Scoffoni, and L. Sack. The determinants of leaf turgor loss point and prediction of drought tolerance of species and biomes: a global meta-analysis. Ecol. Lett., 15(5):393-405, 2012. doi:10.1111/j.1461-0248.2012.01751.x C112

[5] L. Mayor, M. A. Silva, and A. M. Sereno. Microstructural changes during drying of apple slices. Dry. Technol., 23(9-11):2261-2276, 2005. doi:10.1080/07373930500212776 C112, C119

[6] G. H. Crapiste, S. Whitaker, and E. Rotstein. Drying of cellular material-I. A mass transfer theory. Chem. Eng. Sci., 43(11):2919-2928, 1988. doi:10.1016/0009-2509(88)80045-9 C112

[7] H. X. Zhu and J. R. Melrose. A mechanics model for the compression of plant and vegetative tissues. J. Theor. Biol., 221(1):89-101, 2003. doi:10.1006/jtbi.2003.3173 C112

[8] C. X. Wang, L. Wang, and C. R. Thomas. Modelling the mechanical properties of single suspension-cultured tomato cells. Ann. Bot.-London, 93(4):443-453, 2004. doi:10.1093/aob/mch062 C112, C118, C121

[9] N. Wu and M. J. Pitts. Development and validation of a finite element model of an apple fruit cell. Postharvest Biol. Tec., 16(1):1-8, 1999. doi:10.1016/S0925-5214(98)00095-7 C112, C118

[10] G. R. Liu and M. B. Liu. Smoothed Particle Hydrodynamics: A Meshfree Particle Method. World Scientific Publishing Co., Singapore, 2003. http://www. worldscientific.com/worldscibooks/10 .1142/5340 C112, C113, C120

[11] G. R. Liu and Y. T. Gu. An Introduction to Meshfree Methods and Their Programming. Springer, 2005.

http://www . springer com/engineering/computational+ intelligence+and+complexity/book/978-1-4020-3228-8 C112

[12] Y. T. Gu and G. R. Liu. Hybrid boundary point interpolation methods and their coupling with the element free galerkin method. Eng. Anal. 
Bound. Elem., 27(9):905-917, 2003. doi:10.1016/S0955-7997(03)00045-6 $\mathrm{C} 112$

[13] Y. Gu and L. C. Zhang. Coupling of the meshfree and finite element methods for determination of the crack tip fields. Eng. Fract. Mech., 75:986-1004, 2008. doi:10.1016/j.engfracmech.2007.05.003 C112

[14] R. A. Gingold and J. J. Monaghan. Smoothed particle hydrodynamics theory and application to non-spherical stars. Mon. Not. R. Astron. Soc., 181:375-389, 1977.

http://adsabs.harvard.edu/full/1977MNRAS.181_.375G C113

[15] P. Van Liedekerke, P. Ghysels, E. Tijskens, G. Samaey, D. Roose, and H. Ramon. Mechanisms of soft cellular tissue bruising. a particle based simulation approach. Soft Matter, 7:3580-3591, 2011. doi:10.1039/C0SM01261K C113, C116, C117, C118

[16] P. Van Liedekerke, P. Ghysels, E. Tijskens, G. Samaey, B. Smeedts, D. Roose, and H. Ramon. A particle-based model to simulate the micromechanics of single-plant parenchyma cells and aggregates. Phys. Biol., 7:026006, 2010. doi:10.1088/1478-3975/7/2/026006 C113, C116, C117, C118, C120, C121

[17] H. C. P. Karunasena, W. Senadeera, Y. T. Gu, and R. J. Brown. A particle based micromechanics model to simulate drying behaviors of vegetable cells. In Y. T. Gu, S. C. Saha, editor, 4th International Conference on Computational Methods (ICCM 2012), Gold Coast, Australia, 25-28 November, 2012.

http://eprints.qut.edu.au/55471/1/A_Particle_Based_ Micromechanics_Model(ICCM_Gold_Coast).pdf C113

[18] H. C. P. Karunasena, W. Senadeera, Y. T. Gu, and R. J. Brown. A coupled SPH-DEM model for fluid and solid mechanics of apple parenchyma cells during drying. In P. A. Brandner, B. W. Pearce, editor, 18th Australasian Fluid Mechanics Conference, Launceston, Australia, 2012. http://eprints.qut.edu.au/55469/ C113 
[19] H. C. P. Karunasena, W. Senadeera, Y. T. Gu, and R. J. Brown. A coupled SPH-DEM model for micro-scale structural deformations of plant cells during drying. Appl. Math. Model., 2014.

doi:10.1016/j.apm.2013.12.004 C113, C114, C115, C116, C117, C118, C119, C120

[20] H. C. P. Karunasena, W. Senadeera, R. J. Brown, and Y. T. Gu.

Simulation of plant cell shrinkage during drying - a SPH-DEM approach. Eng. Anal. Bound. Elem., 44:1-18, 2014.

doi:10.1016/j.enganabound.2014.04.004 C113, C114, C115, C116, C117, C118, C119

[21] H. C. P. Karunasena, P. Hesami, W. Senadeera, Y. T. Gu, R. J. Brown, and A. Oloyede. Scanning electron microscopic study of microstructure of gala apples during hot air drying. Dry. Technol., 32(4):455-468, 2014. doi:10.1080/07373937.2013.837479 C118, C119

[22] A. Stukowski. Visualization and analysis of atomistic simulation data with OVITO - the open visualization tool. Model. Simul. Mater. Sc., 18:015012, 2010. doi:10.1088/0965-0393/18/1/015012 C120

[23] P. W. Cleary and J. J. Monaghan. Conduction modelling using smoothed particle hydrodynamics. J. Comput. Phys., 148(1):227-264, 1999. doi:10.1006/jcph.1998.6118 C120, C121

[24] L. Taiz and E. Zeiger. Plant Physiology, chapter Water and Plant Cells, pages 73-84. Sinauer Associates, Sunderland, USA, 2010. C121

[25] H. C. P. Karunasena, W. Senadeera, R. J. Brown, and Y. T. Gu. A particle based model to simulate microscale morphological changes of plant tissues during drying. Soft Matter, 2014. doi:10.1039/C4SM00526K C133 


\section{Author addresses}

1. H. C. P. Karunasena, School of Chemistry Physics and Mechanical Engineering, Faculty of Science and Engineering, Queensland University of Technology, Brisbane, Australia; Department of Mechanical and Manufacturing Engineering, Faculty of Engineering, University of Ruhuna, Hapugala, Galle, Sri Lanka.

mailto: chaminda@mme.ruh.ac. Ik

2. W. Senadeera, School of Chemistry Physics and Mechanical Engineering, Faculty of Science and Engineering, Queensland University of Technology, Brisbane, Australia.

mailto:w3. senadeera@qut.edu . au

3. R. J. Brown, School of Chemistry Physics and Mechanical Engineering, Faculty of Science and Engineering, Queensland University of Technology, Brisbane, Australia.

mailto:richard.brown@qut.edu.au

4. Y. T. Gu, School of Chemistry Physics and Mechanical Engineering, Faculty of Science and Engineering, Queensland University of Technology, Brisbane, Australia.

mailto:yuantong.gu@qut.edu.au 